\title{
BMJ Open Fostering humanism: a mixed methods evaluation of the Footprints Project in critical care
}

\author{
Neala Hoad, ${ }^{1}$ Marilyn Swinton, ${ }^{2}$ Alyson Takaoka, ${ }^{2}$ Benjamin Tam, ${ }^{1,3,4}$ \\ Melissa Shears, ${ }^{5}$ Lily Waugh, ${ }^{1}$ Feli Toledo, ${ }^{6}$ France J Clarke, ${ }^{2}$ \\ Erick Huaileigh Duan, ${ }^{1,3,4}$ Mark Soth, ${ }^{1,3}$ Deborah J Cook ${ }^{1,2,3}$
}

To cite: Hoad N, Swinton M, Takaoka A, et al. Fostering humanism: a mixed methods evaluation of the Footprints Project in critical care. BMJ Open 2019:9:e029810. doi:10.1136/ bmjopen-2019-029810

- Prepublication history and additional material for this paper are available online. To view these files, please visit the journal online (http://dx.doi. org/10.1136/bmjopen-2019029810).

Received 28 February 2019

Revised 24 July 2019

Accepted 25 September 2019

Check for updates

(C) Author(s) (or their employer(s)) 2019. Re-use permitted under CC BY-NC. No commercial re-use. See rights and permissions. Published by BMJ.

${ }^{1}$ Department of Critical Care, St. Joseph's Healthcare Hamilton, Hamilton, Ontario, Canada

${ }^{2}$ Department of Health Research Methods, Evidence and Impact, McMaster University, Hamilton, Ontario, Canada

${ }^{3}$ Department of Medicine, McMaster University, Hamilton, Ontario, Canada

${ }^{4}$ Department of Critical Care,

Niagara Health System, St.

Catharines, Ontario, Canada

${ }^{5}$ Department of Medicine,

Queen's University, Kingston,

Ontario, Canada

${ }^{6}$ Department of Spiritual Care, St. Joseph's Healthcare, Hamilton, Ontario, Canada

Correspondence to

Neala Hoad;

nealahoad@gmail.com

\section{ABSTRACT}

Objectives The objectives of this mixed-methods study were to assess the uptake, sustainability and influence of the Footprints Project.

Setting Twenty-two-bed university-affiliated ICU in Hamilton, Canada.

Participants ICU patients admitted and their families, as well as clinicians.

Interventions We developed a personalised patient Footprints Form and Whiteboard to facilitate holistic, patient-centred care, to inform clinical encounters, and to create deeper connections among patients, families and clinicians.

Outcome measures We conducted 3 audits to examine uptake and sustainability. We conducted semi-structured interviews with 10 clinicians, and held 5 focus groups with 25 clinicians; and we interviewed 5 patients and 13 family representatives of 5 patients who survived and 5 who died in the ICU. Transcripts were analysed using qualitative content analysis.

Results The Footprints Project facilitated holistic, patient-centred care by setting the stage for patient and family experience, motivating the patient and humanising the patient for clinicians. Through informing clinical encounters, Footprints helped clinicians initiate more personal conversations, foster deeper connections and guide treatment. Professional practice influences included more focused attention on the patient, enhanced interdisciplinary communication and changes in community culture. Initially used in $15.8 \%$ of patients (audit A), uptake increased to $51.4 \%$ in audit B, and was sustained at $57.8 \%$ in audit C.

Conclusions By sharing valuable personal information about patients before and beyond their illness on individualised whiteboards at each bedside, the Footprints Project fosters humanism in critical care practice.

\section{INTRODUCTION}

Barriers to patient self-expression can engender a loss of identity, creating distance between patients and clinicians. ${ }^{1}$ Difficulty that clinicians may have acknowledging their shared humanity with patients may contribute to clinician detachment. ${ }^{2}$ Such disengagement may serve as self-protection while working in an emotional environment, ${ }^{3}$

\section{Strengths and limitations of this study}

- Mixed-methods design informed by interdisciplinary engagement, and representative views of patients, family members and clinicians.

- Multimodal enabling and reminding approach to enhance and sustain uptake.

- The Footprints Project supports individualised care at the end-of-life for dying patients and their families, complementing palliative care interventions in our unit such as the 3 Wishes Project, aligning with dignity-conserving care by humanising patients whether they survive or succumb.

- Includes a modest number of patient and family interviews.

- Clinicians cautioned that reading the Footprints tools should not replace spontaneous, authentic dialogue.

but attenuate empathy. ${ }^{3}$ In the intensive care unit (ICU), life-sustaining technologies causing communication challenges can also dehumanise patients.

Information that patients and families want shared with the healthcare team may be revealed by questionnaires, refocusing attention on personhood. For hospital-based palliative care, Chochinov et al developed the Patient Dignity Question (PDQ) ${ }^{2}$ - a single open-ended question, "What do I need to know about you as a person to give you the best care possible?" The resulting patientpartnered paragraph is placed on the chart. Clinicians reported learning something new about patients, influencing care; families recommended using the PDQ. These investigators developed a 10-item instrument documenting personal attributes called 'This is ME' (TIME). ${ }^{4}$ Most residents canvassed in six nursing homes recommended using TIME, and wanted the summary placed in their chart. Clinicians stated that TIME enhanced their respect and compassion for patients.

Communication boards can also express patients' personhood. Gerontology nurses 
introduced the 'All About Me' board for persons with dementia unable to speak for themselves, ${ }^{5}$ offering families the opportunity to express their loved one's personality and preferences on a board installed in the patient's room. An ICU study found that conscious patients who offer information to place on their communication board may be more satisfied with care. ${ }^{6}$

We developed the Footprints Project to promote the personhood of critically ill patients, hypothesising this could be actualised by a combined written tool (Footprints Form) and communication board (Footprints Whiteboard). The overall goals of the Footprints Project were to facilitate holistic, patient-centred care, inform clinical encounters and create deeper connections among patients, families and clinicians. Building on extensive pilot work, ${ }^{7-9}$ we incorporated Footprints into daily practice in the ICU at St. Joseph's Healthcare Hamilton.

The objectives of this study were to assess the (1) uptake, (2) sustainability and (3) influence of the Footprints Project using both qualitative and quantitative methods.

\section{METHODS}

\section{Setting}

The Footprints Project was a nursing-led interprofessional initiative in a 22-bed university-affiliated, medical-surgical ICU at St. Joseph's Healthcare Hamilton.

\section{Intervention}

The Footprints Form documents personal information about a patient's story in a structured 16-item questionnaire completed by family members or friends (or patients, if able) (online supplementary file 1). The second component involves transcription of key information from the form onto a dedicated Footprints Whiteboard in each patient's room. The completed Footprints Form is placed in the medical chart. Both components were developed following engagement and feedback from key stakeholders, 6-phase pilot testing (table 1) and baseline completion measurements (January 2015December 2016). Based on low uptake in our pilot audit (audit A) (July 2016) and implementation challenges discovered during pilot testing, we introduced 10 strategies to enhance project uptake (January to July 2017) (table 2).

\section{Quantitative methods}

Audit B (June 2017) was conducted to evaluate project uptake (objective 1). We defined successful form and whiteboard uptake as a statistically significant increase in completion rates between audits A and B. We chose this definition for feasibility purposes based on low uptake in pilot data and barriers identified during pilot work (table 2). Audit C (May 2018) was conducted to measure sustainability (objective 2) and was defined as a statistically significant increase or no change in completion rates from audit B to C. Each audit documented patient data (eg, mechanical ventilation, length of stay) and
Footprints data (eg, completed questions on the form and transposition of pertinent information onto the whiteboard). We defined a completed form as having $\geq 1$ question completed. This low threshold was defined to respect the invitational, non-coercive nature of the form, but typically most questions were completed. Audit A was a 1 day, concealed audit; audits B and C followed patients over a $\leq 5$-day observation period, informing bedside staff to concurrently elicit feedback.

\section{Qualitative methods}

To understand the influence (objective 3) of the Footprints Project on ICU clinicians, we conducted 10 semi-structured interviews (10 clinicians) and 5 focus groups (25 clinicians), between audits B and C. Clinicians included three bedsides nurses, 1 charge-nurse, 4 physiotherapists, 2 respiratory therapists, 2 chaplains, 1 clerk and 12 physicians ( 5 fellows, 4 residents, 3 intensivists). We used purposive sampling to identify interdisciplinary clinicians working in the ICU for $\geq 1$ year (except trainees), inviting participation by email. All invited clinicians participated.

To explore the influence of the Footprints Project on the experience of patients and family members, we interviewed 5 survivors on the ward and 13 family members of 10 different patients ( 5 families of survivors and 5 families of decedents). Selection criteria were English-speaking patients in ICU for $\geq 1$ week with completed whiteboards. Participation was by telephone or in-person. All invited patients and families participated. We conducted interviews until data saturation was reached and no further themes emerged in our analysis.

A lead researcher with qualitative methods training who does not work in the ICU (MS) and had no prior relationship with participants conducted interviews and focus groups in a hospital office or conference room; one family member was interviewed by telephone. A nurse $(\mathrm{NH})$ and physician (DJC) with qualitative methods training interviewed five patients they previously cared for. Semi-structured interview and focus group guides were used; each interviewer kept field notes from the focus groups and interviews. Interviews and focus groups were digitally recorded, transcribed and anonymised.

See online supplementary file 2 for a timeline of quantitative and qualitative activities.

\section{Analysis}

We assessed uptake by calculating the proportion of completed Footprints activities in audit B (eg, completion of the form, information transposed onto the whiteboard) to audit A. Whiteboard data were analysed in two information categories: dynamic (information updated daily, ie, date, nurse, physician, respiratory therapist and physiotherapist) with a denominator of total patient audit days, or static (information that remained constant over the ICU stay, ie, presence of photos, patient name, spokesperson, goals, messages, about me) with a denominator of total patients. We evaluated sustainability by 


\begin{tabular}{|c|c|c|}
\hline Phase & Methods & Results \\
\hline 1 & $\begin{array}{l}20 \text { semi-structured interviews with ICU staff to } \\
\text { generate items for the Footprints Form } \\
8 \text { nurses, } 2 \text { physicians, } 5 \text { respiratory therapists, } 2 \\
\text { physiotherapists, } 1 \text { chaplain, } 1 \text { medical student and } 1 \\
\text { research coordinator }\end{array}$ & $\begin{array}{l}\text { Paper-based form was favoured. } \\
\text { Form to be placed in common location (ie, front of the } \\
\text { medical chart). } \\
\text { Selected items from form transcribed onto whiteboard } \\
\text { in the patient's room. } \\
\text { Photo of the patient encouraged was for the } \\
\text { whiteboard. }\end{array}$ \\
\hline 2 & $\begin{array}{l}\text { The Footprints Whiteboards were installed in patients' } \\
\text { rooms to display essential information from the } \\
\text { Footprints Form } \\
\text { The Footprints Form was pilot tested with the families } \\
\text { of } 16 \text { patients }\end{array}$ & $\begin{array}{l}16 \text { patients aged } 48-89 \text { years (mean } 67.1 \text { years) were } \\
\text { included. } \\
5 \text { families (participation rate } 93.8 \% \text { ) completed the form } \\
\text { ( } 7 \text { interviewer-administered and } 8 \text { self-administered). } \\
\text { Whiteboard data: the date, the patient's preferred } \\
\text { name, clinician, name of the family spokesperson, aids } \\
\text { used at home, milestones in the patient's life, important } \\
\text { issues to share and a message centre for family and } \\
\text { ICU team. }\end{array}$ \\
\hline 3 & $\begin{array}{l}\text { The Footprints Form and Whiteboard was } \\
\text { administered for } 26 \text { additional patients } \\
\text { Feedback was elicited from family members (verbal } \\
\text { and written) and clinicians (verbal) }\end{array}$ & $\begin{array}{l}21 \text { families and } 30 \text { clinicians (response rates } 80.4 \% \text {, } \\
100 \% \text {, respectively). } \\
\text { Footprints was perceived to foster holistic, personalised } \\
\text { care and promote humanism in practice. }\end{array}$ \\
\hline 4 & $\begin{array}{l}\text { Footprints Form was used by clinicians on the unit for } \\
5 \text { months }\end{array}$ & $\begin{array}{l}\text { During this period, nurses provided Footprints Forms } \\
\text { to families of patients admitted to the ICU and updated } \\
\text { the Whiteboards with selected information provided. }\end{array}$ \\
\hline 5 & $\begin{array}{l}\text { A positive deviance group brainstorming exercise with } \\
16 \text { interdisciplinary colleagues was held } \\
\text { Strategies were identified to encourage completion } \\
\text { of the Footprints Forms and Whiteboards, and to } \\
\text { generate additional implementation suggestions }\end{array}$ & $\begin{array}{l}\text { Several strategies were generated to increase } \\
\text { completion (eg, better accessibility of forms for unit } \\
\text { communication clerks and clinicians for distribution, } \\
\text { and providing forms in patient rooms and waiting room } \\
\text { for families to complete). More results are found in } \\
\text { table } 3 \text {. }\end{array}$ \\
\hline
\end{tabular}

ICU, intensive care unit.

comparing the proportion of completed Footprints activities between audits B and C using Pearson's $\chi^{2}$ test with a significance level of $p<0.05$. All statistics were conducted in SPSS (SPSS Statistics for Windows, V.24.0, IBM, Armonk, New York, USA)

For interview and focus group data, conventional content analysis was used, whereby codes are derived directly from the data without preconceived categories or theoretical perspectives, ${ }^{10}$ yielding a descriptive summary of findings, consistent with qualitative description. ${ }^{11}$ Three investigators completed line-byline open coding of one focus group and five interview transcripts, discussed resulting codes and developed the preliminary coding list. Remaining transcripts were coded by a single investigator using an audit trail documenting changes $^{12}$; the coding structure evolved during team consensus meetings. N'Vivo (V.11.0) was used for data management. We held an off-site member-checking event with 10 interprofessional colleagues who were not previously interviewed to share qualitative results and verify whether findings accurately reflected their experiences and perceptions of the Footprints Project.

\section{Ethics}

Written informed consent was obtained from all participants. 
Table 2 Ten footprints implementation strategies

\begin{tabular}{|c|c|c|}
\hline Challenge & Implementation strategy & Description \\
\hline $\begin{array}{l}\text { Low visibility of paper } \\
\text { forms }\end{array}$ & $\begin{array}{l}\text { Print on brightly coloured green } \\
\text { paper }\end{array}$ & $\begin{array}{l}\text { The Footprints Form was printed on bright green paper as a visual } \\
\text { prompt. }\end{array}$ \\
\hline $\begin{array}{l}\text { No accountability for } \\
\text { form distribution }\end{array}$ & $\begin{array}{l}\text { Involve the unit communication } \\
\text { clerk }\end{array}$ & $\begin{array}{l}\text { The unit communication clerks placed the blank Footprints Form in } \\
\text { each new patient's chart on admission. }\end{array}$ \\
\hline $\begin{array}{l}\text { Lack of form } \\
\text { availability }\end{array}$ & $\begin{array}{l}\text { Make the form available in } \\
\text { patient room }\end{array}$ & $\begin{array}{l}\text { Blank Footprints Forms were hung from the Whiteboard with a note } \\
\text { attached for families 'Please take a form to complete and return to } \\
\text { the nurse'. }\end{array}$ \\
\hline $\begin{array}{l}\text { Lack of form } \\
\text { availability }\end{array}$ & $\begin{array}{l}\text { Make the form available in } \\
\text { waiting room }\end{array}$ & $\begin{array}{l}\text { The Footprints Forms were also placed in the ICU waiting room } \\
\text { inviting family completion. }\end{array}$ \\
\hline $\begin{array}{l}\text { Not part of routine } \\
\text { care }\end{array}$ & Include in Daily Goals Checklist ${ }^{23}$ & $\begin{array}{l}\text { A Footprints completion prompt was added to the Daily Goals } \\
\text { Checklist. }\end{array}$ \\
\hline $\begin{array}{l}\text { Lack of nurse } \\
\text { motivation }\end{array}$ & $\begin{array}{l}\text { Share family feedback with } \\
\text { nurses via email }\end{array}$ & $\begin{array}{l}\text { A synopsis and stories about Footprints family feedback were } \\
\text { periodically emailed to each bedside RN. }\end{array}$ \\
\hline Staff forgetfulness & $\begin{array}{l}\text { Remind staff about Footprints in } \\
\text { ICU newsletter }\end{array}$ & $\begin{array}{l}\text { The Footprints Project was featured in the 'Practice Polisher' } \\
\text { newsletter. }\end{array}$ \\
\hline Staff forgetfulness & $\begin{array}{l}\text { Role-modelling use of Footprints } \\
\text { in practice }\end{array}$ & $\begin{array}{l}\text { Team members more attentively used the Footprints Form and } \\
\text { Whiteboard in practice to encourage uptake. }\end{array}$ \\
\hline Staff forgetfulness & $\begin{array}{l}\text { Include verbal reminders during } \\
\text { huddles with bedside staff }\end{array}$ & $\begin{array}{l}\text { In small group huddles and ICU walk-abouts, the research team gave } \\
\text { ongoing verbal reminders about Footprints. }\end{array}$ \\
\hline Lack of awareness & $\begin{array}{l}\text { Ongoing interprofessional } \\
\text { engagement }\end{array}$ & $\begin{array}{l}\text { The research team collaborated with ICU clinicians, palliative care } \\
\text { and liaison psychiatry colleagues for feedback and improvement } \\
\text { suggestions. }\end{array}$ \\
\hline $\begin{array}{l}\text { Lack of nursing time } \\
\text { to complete form }\end{array}$ & $\begin{array}{l}\text { Introduce volunteer to engage } \\
\text { families to replace former step* }\end{array}$ & $\begin{array}{l}\text { Twice weekly, a volunteer (former ICU nurse) checked patient rooms } \\
\text { for completed Footprints and Whiteboards, distributing blank forms } \\
\text { to family members as needed, encouraging their completion and } \\
\text { return to the bedside nurse. }\end{array}$ \\
\hline
\end{tabular}

*In July 2017, the 10th step was changed from 'A reminder will be given to the nurses to distribute the Footprints Form and complete the Whiteboard as part of the ICU safety briefing' to the volunteer-led family engagement.

ICU, intensive care unit.

\section{RESULTS}

\section{Quantitative results: uptake and sustainability}

Reflecting the pilot phase, audit A showed use of the Footprints Form and Whiteboard for $9 / 57$ patients (15.8\%). Following 10 implementation strategies, form completion increased significantly (audit B, 36/70 patients, $51.4 \%$ ) $(\mathrm{p}<0.001)$. Overall form completion rate was sustained between audits B $(51.4 \%)$ and $\mathrm{C}(37 / 64$ patients, $57.8 \%)$ $(\mathrm{p}=0.604)$ (table 3$)$. Using patient-days in audits B $(n=242)$ and $C(n=247)$, there were no significant differences in dynamic information completion except for a decrease in names of respiratory therapists $(\mathrm{p}=0.002)$. For patients in audits B $(n=70)$ and C $(n=64)$, some static whiteboard data completion rates were unchanged; however, messages, spokesperson and daily goals on the board declined (table 4).

\section{Qualitative results: uptake and sustainability}

The uptake and sustainability of the Footprints Project were discussed during the focus groups and interviews.

Initially, clinician views on Footprints utilisation reflected inconsistent uptake:
I think it's also to do with modeling ... So, for example, nobody is even bothering to look at this whiteboard, the nurses are not bringing it up. You, as a team, are completely disconnected from it whether it's filled out well or not...If (physician name) is on, of course, or, if ( $\mathrm{RN}$ names) are at the bedside...the reminders are going to be there. (Fellow)

Clinicians identified implementation challenges which we grouped into patient-level, clinician-level and system-level barriers (table 5). Clinicians expressed how gradually, the Footprints Project became integrated into practice.

One physiotherapist shared: "I totally believe it's sustainable. It's become core. It's certainly become an important part of how I function from day to day in the ICU”. (Physiotherapist)

A physician described:

It's common place now, for there to be not just something on the board but something in the room that's important to, or comforts, that person, whereas I think that used to be more the exception and not the standard. I think what (Footprints) does is it makes 
Table 3 Footprints Form audit completion rates

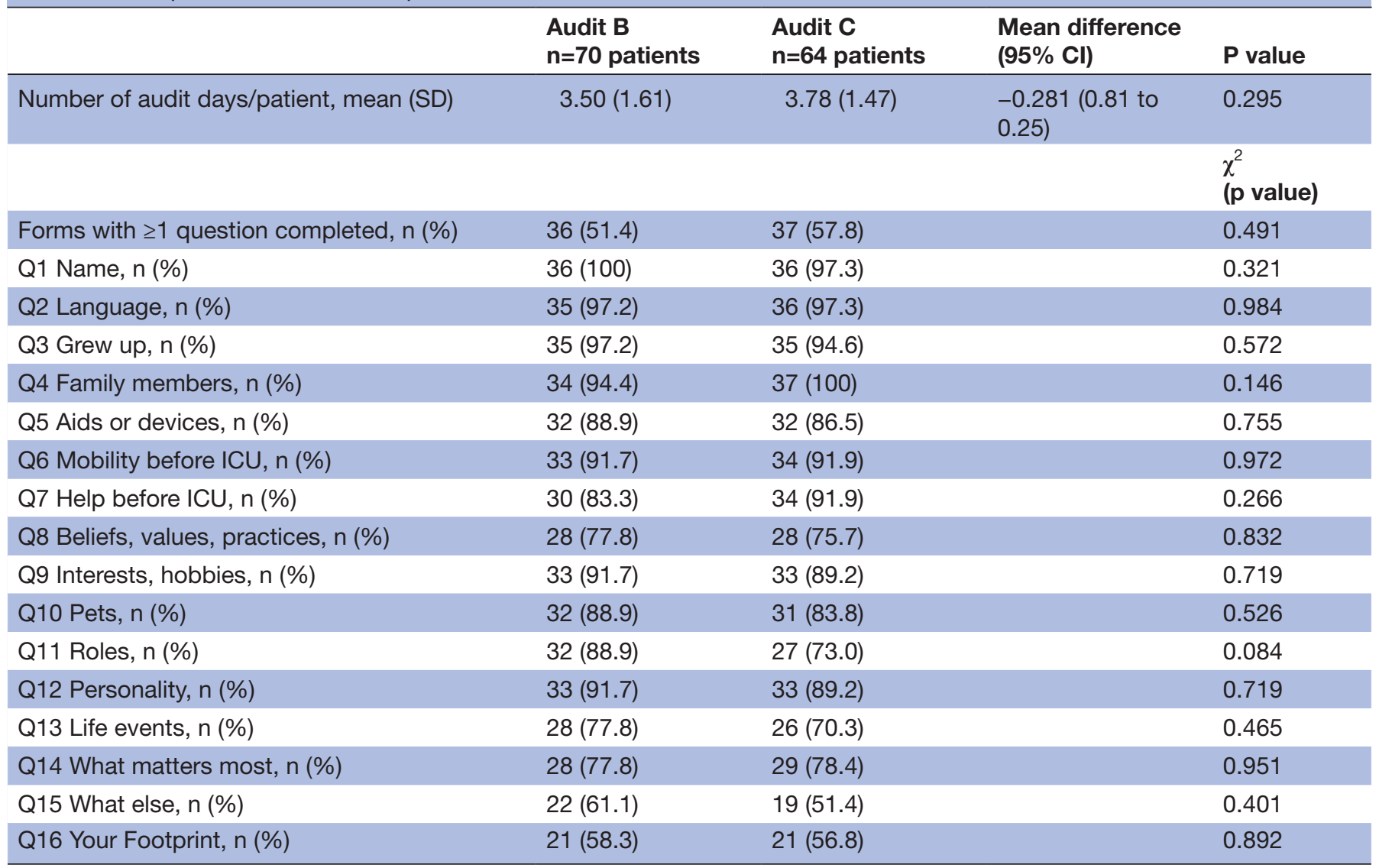

ICU, intensive care unit.

establishing that understanding of the patient as an expectation... So instead of when it's been there, seeing it as a bonus, when it's not there, it's seen as the exception. (Physician)

\section{Qualitative results: influence}

Patients and family members described how Footprints influenced their experience. Clinicians reported diverse purposes of the Footprints Project, with beneficial consequences. The themes and subthemes from the analysis of the qualitative data on influence are illustrated in online supplementary file 3 .

Facilitating holistic, patient-centered care

The Footprints Project sets the stage for the patient and family, motivates the patient and humanises the patient for clinicians.

\section{Setting the stage}

A patient shared feeling respected as an individual to have the team know personal information about him:

To me, it felt like, when they looked at it, they were looking at me - no more as a patient...they were looking at me as a family man; a dad, a husband, an uncle, a brother... I wasn't just 'that patient in Room 4'. (Patient)
One family member referred to how Footprints 'set the tone' for her sister's care. (. Another described:

For me, it was a footprint to what was coming...They really want to get to know you and your family, and they just carried on all the way down...they involved us in everything. (Son)

Being invited to call the patient by their preferred name, as described by a physiotherapist, started the relationship on a different footing, offering 'permission to be on a different level with the patient'. (Physiotherapist)

\section{Motivating the patient}

Patients and families identified how the whiteboard stimulated the patient's recovery. A partner explained:

I feel that it triggered (my husband). Like...certain things he loves and familiar names and things like that. It triggers something in their brain to think, 'Oh yeah, I do have that. I do have that to fight for'. (Wife)

A patient affirmed the inspirational effect of the whiteboard:

For me, personally, it helped because it gave me something to wake up to, and gave me something to work towards...It helps with, you know, motivation and drive and, you know, staying on that road to recovery. (Patient)

A nurse explained how whatever struggle patients are going through, 
Table 4 Footprints Whiteboard audit completion rates

\begin{tabular}{|c|c|c|c|}
\hline & $\begin{array}{l}\text { Audit B } \\
n=70 \\
\text { patients }\end{array}$ & $\begin{array}{l}\text { Audit C } \\
\mathrm{n}=64 \\
\text { patients }\end{array}$ & $\begin{array}{l}\chi^{2} \\
\text { (P value) }\end{array}$ \\
\hline Picture n (\%) & $10(14.3)$ & $8(12.5)$ & 0.762 \\
\hline $\begin{array}{l}\text { Patient name } \mathrm{n} \\
(\%)\end{array}$ & $63(90.0)$ & $58(90.6)$ & 0.903 \\
\hline $\begin{array}{l}\text { Spokesperson } \\
\text { n (\%) }\end{array}$ & $41(58.6)$ & 25 (39.1) & $0.024^{*}$ \\
\hline Goals n (\%) & $9(12.8)$ & $2(3.1)$ & $0.040^{\star}$ \\
\hline Messages n (\%) & 30 (42.9) & $15(23.4)$ & $<0.001^{*}$ \\
\hline About me n (\%) & $29(41.4)$ & $34(53.1)$ & 0.107 \\
\hline \multicolumn{4}{|l|}{${ }^{*} p<0.05$} \\
\hline & $\begin{array}{l}\text { Audit } B \\
\mathrm{n}=247 \\
\text { patient audit } \\
\text { days }\end{array}$ & $\begin{array}{l}\text { Audit } C \\
\mathrm{n}=242 \\
\text { patient audit } \\
\text { days }\end{array}$ & $\begin{array}{l}\chi^{2} \\
\text { (P value) }\end{array}$ \\
\hline Date n (\%) & $224(90.7)$ & 216 (89.3) & 0.598 \\
\hline $\mathrm{RN} n(\%)$ & $223(90.2)$ & $219(90.5)$ & 0.936 \\
\hline MD n (\%) & $216(87.4)$ & $209(86.4)$ & 0.722 \\
\hline RT n (\%) & $169(68.4)$ & $132(54.5)$ & $0.002^{*}$ \\
\hline PT n (\%) & $19(11.4) \dagger$ & 25 (12.6)‡ & 0.731 \\
\hline
\end{tabular}

We excluded weekends and holidays in calculating the patient audit days denominator for physiotherapist name within dynamic whiteboard completion rates.

${ }^{*} \mathrm{p}<0.05$

†Audit $B$ denominator: $\mathrm{n}=166$ days.

¥Audit $\mathrm{C}$ denominator: $\mathrm{n}=198$ days.

It makes you fight with them... We had a young woman who had two young children and every time you'd look at those pictures, you're like, 'Come on! You gotta do it! You gotta do it for these kids!' (Nurse)

Physiotherapists and respiratory therapists reported using Footprints to incentivise rehabilitation:

We use it to kind of distract them and get them thinking about something more positive so, knowing that they love gardening... like, 'Do you buy your plants or do you grow them from seed?'... it's just really helpful for us in getting more out of the patient because otherwise, when they're so focused on...'I'm breathing too fast', or 'I'm feeling anxious', then we don't get as much out of them in therapy. So I find that the whiteboard is helpful in getting them to do more than they thought that they were capable of doing or what we would have been capable of doing if we hadn't had those cues to kind of ask them and get them engaged. (Physiotherapist)

\section{Humanising the patient}

Families perceived that the Footprints Project broadened clinician perspectives. A parent commented:

I like it (the whiteboard), because then they know something about her, not that she's just this person that lays in the bed and doesn't move...that she does have feelings, she does have things she's enjoyed; she does have a life. Because a lot of people say, 'Well, you know, she hasn't got much life. She's stuck in a wheelchair'. Hey, this girl's on the go all the time. She loves karaoke. (Mother)

A nurse stated, "To know that person, on a personal level, it just makes everything... not easier, but better, in a way that you kind of can relate to them...to humanize them in a way that you may not have known".

Whiteboard statements may challenge assumptions.

As nurses, we form our own opinions a lot of the time, based on someone's history... then you can see on the whiteboard, oh, this person was an artist. Like, we had a really young guy pass away last week...you can read his history and kind of form your own opinions, or you can go in his room and see...all the artwork he had and how... artsy and smart and what kind of person he was. I think that changes it a little bit. (Nurse)

A resident shared:

I actually realized, when I came here... I was getting like, pretty crusty and pretty cold and removed from patients...And I never intended it to be like that... so...in that sense, that is what (Footprints) does for you-(it) humanizes the patient... (Resident)

Table 5 Footprints: implementation challenges identified by clinicians

Patient/Family-level challenges

Patient too unstable; other care priorities

Patient or family language barrier

Perception that family is too distressed Patient has no family or friend available

\section{Clinician-level challenges}

Clinicians unsure of how to explain form. Clinicians concern that it will not be well received.

Clinicians too busy to hand out or review form or abstract information for whiteboard.

Perceived nursing ownership of the whiteboard; other clinicians reluctant to write on board.

\section{System-level challenges}

Completed forms not kept in consistent location.

Form and whiteboard completion not considered mandatory or enforced. Considered unnecessary for patients who are able to communicate themselves. Considered unnecessary for patients with a very short ICU stay.

ICU, intensive care unit. 
Informing clinical encounters

The Footprints Project was perceived as influencing clinical encounters by helping to start conversations, foster deeper relationships and guide treatment.

\section{A conversation-starter}

Clinicians described using Footprints as a springboard. As relayed by a nurse, "it is a good conversation-starter with that patient...like, 'So, you travelled. I also travel. Let's talk about traveling while I get you washed up'. (Nurse)

Giving family members the Footprints Form was considered a way to build rapport with families:

Like, that's usually how I introduce myself-especially if they're new to the unit... I kind of want to start building that relationship of trust...'We would like to get to know you'. And usually that's a good ice breaker, I find. (Nurse)

A patient's sister described:

So I think at first, like, you kind of wonder if there might have been a lot of stigma around him-you know, just an addict, or whatever, and...I think what (Footprints) triggered was conversation between us and the healthcare team...you've got a structure that helps them focus on the... unique things about that person they're caring for. (Sister)

A physician expressed the utility of information taken directly from the family:

You get to use that as your leaping off point...If you're like 'Oh! I see you like crosswords! Have you done any crosswords this week?' I think it is interpreted as friendlier too, because when you already know someone they're more engaged with you as opposed to when you just pick a random question and hope you're hitting in the right direction. (Physician)

\section{Fostering deeper relationships}

Some clinicians articulated how learning about their patients through Footprints adds another dimension to care:

They become less of a patient and more of someone you want to help once you kind of learn a little bit more about them. I don't know, maybe you get a little bit more, not emotional, but invested in their care. (Respiratory therapist)

Families and staff described how the whiteboard influenced connections. A sibling reflected:

I think it helped improve and just strengthen the bond....and that trust. Knowing that...my family member was being cared for-not only on the clinical side but as a human being-that genuine care of humanity...I think it strengthened the relationship and gave us comfort as well. (Sister)

One physician shared:
It allows me to establish a connection with either the patient or their family members in a more meaningful way, as well as more quickly...so it's not just the time it would take, but it's the type of relationship that you might get early on. (Physician)

Clinicians believed that Footprints facilitates more emotional engagement with patients. Dismissing a potential concern that this could create inappropriate attachment, one fellow added: "I think, if anything, understanding your patient's background better leads to greater job satisfaction making my job more interesting, sometimes even more fun..." (Fellow)

\section{Guiding treatment}

Staff indicated how Footprints guides their therapy. One physiotherapist described how knowing more personal information informs treatment targets:

In your mind, when you're working with them, you have a better sense of, like, we're trying to get you back to your wife and your grandkids that you love so much... You actually can visualize the goal that you're working towards. (Physiotherapist)

A respiratory therapist shared:

There's been times that they've written on the board that the patient is anxious or claustrophobic (and) you kind of slow down, like maybe if you're putting someone on BiPAP and you're putting a big mask on their face and you've just seen that they're claustrophobic, you take that into account...you slow down and explain things a little bit better. (Respiratory therapist)

A physiotherapist underscored the utility of knowing a patient's comorbidities and assistive devices (eg, hearing aids), "because all of those things might impact how we help them recover... So we can almost cue up the patient to be as optimized as possible”. (Physiotherapist)

The whiteboard can be useful for goals-of-care meetings to learn more about function, interests and family. A nurse highlighted how a conversation about what a patient 'liked and loved and lived' (nurse) was foundational during the dying process.

A resident described how a Footprints Form informed a late-night conversation with a man he met for the first time:

... (it) really framed the conversation I had next...he loved gardening and now he's here, about to be on a ventilator... and he was quite elderly...the prognosis was poor. Even though he had been deteriorating, he understood that. We could have a discussion and we ended up not being aggressive and he passed away that night, actually. (Resident)

\section{Influencing professional practice}

Footprints was perceived as influencing practice by refocusing clinician attention on personhood, enhancing 
interdisciplinary communication and changing community culture.

\section{Refocusing attention on personhood}

A physician found that Footprints can bridge that divide that can develop between patients and clinicians,

Because as you move through medicine, it's very easy to get more black and white on the medical issues and forget everything else. And if you have particularly bad weeks or bad times in the unit, you can hide behind medical facts... as a protective mechanism for sort of your emotional well-being... And you try to detach, but stuff like that brings you back to relate to families as a human being, not as a physician anymore, not as a scientist giving numbers on prognosis. (Physician)

As described by a nurse, Footprints encourages more intimate, less structured, task-oriented practice:

It just becomes so routine and mechanical that you sometimes forget that there's a body and someone's mother and someone's child sitting in front of you and I think that board brings you back to, 'Oh my God, this is a person. This isn't just a job anymore. Like, I'm actually taking care of someone's loved one'. So, I think it's a really good reminder of that. (Nurse)

A resident reflected that Footprints helped to refocus on personhood, "It's not like you're changing what you're doing, it just has more meaning... it's less like you are treating numbers". (Resident)

\section{Enhancing interdisciplinary communication}

Most clinicians discussed how the whiteboard enhances team communication. One physician commented, "Everybody from the physios to the nurses to speech-language pathologists-it puts us all on the same page in our common conversation about that patient". (Physician)

A physician shared how the whiteboard information promoted interdisciplinary exchange:

So it's sometimes nice to see, the therapists have written things on the board like you know, '(she) went $1.5 \mathrm{~km}$ on the bike today'. I wouldn't have otherwise known that to be honest, because I wouldn't have otherwise looked through the therapy documentation. ...So I think it has helped the interdisciplinary team approach. (Physician)

\section{Changing community culture}

Clinicians described how Footprints created an enhanced sense of community, as a physician noted:

It's nice to remind people, 'hey it's so-and-so's birthday tomorrow or so-and-so's anniversary'. It's nice to hear those vibes through the unit-I think there has been a cultural change. I think it has changed the unit. (Physician)
A nurse explained the influence of Footprints in the ICU:

We've always asked, 'Tell me about them', you know, 'What do they like?'... But now it's kind of like a standard...so, there's more discussions about, I would say, who the person is rather than (just) what is going on medically. So, I think it's impacted the unit in a good way. (Nurse)

A fellow who returned to the unit after several years away observed:

I definitely think the culture has changed in the last three to 4 years...There's a lot more emphasis now on getting to know our patients and the humanism aspect of our medical practice than there was... It's quite different than the cultures in the other units. (Fellow)

\section{DISCUSSION}

Clinicians working in the ICU may inadvertently forget the 'lives lived' of their patients. The Footprints Project shares each patient's story or 'footprint' with the healthcare team via the Footprints Form, typically completed by families to capture personal information (eg, preferred name and hobbies). Then selected information is transcribed onto a dedicated Footprints Whiteboard in the room. We documented how Footprints inspired patients and families, and also sparked the ICU team to further motivate the patient. Footprints enhanced multidisciplinary exchange by sharing of important information about patients' background, social and family rolesvalued by seriously ill patients. ${ }^{13}$

Qualitative data indicate more endorsement of Footprints than the quantitative data suggest. Use of the Footprints Form and Whiteboard was low in the pilot phase, then a $37 \%$ absolute increase in form completion occurred following implementation strategies (audit A: $15 \%$, audit B: $51 \%$ ), that was sustained (audit C: $58 \%$ ), although personal whiteboard messages, spokesperson and daily goals declined, perhaps reflecting the interim introduction of a hospital-wide electronic clinical information system. Nonetheless, the sustained overall Footprints completion through this transition lends support to its integration, which remains paper and whiteboardbased rather than web-based. As an inviting repository of information for patients and families to share with the healthcare team and vice versa, this tactile, accessible, initiative reportedly stimulated story-telling ${ }^{14}$ and re-invigorated partnerships among the staff, and with patients and families.

If dignity represents the inherent worth of all human beings, and respect represents the actions that appropriately honour and acknowledge such dignity, ${ }^{15} 16$ this conceptualisation can facilitate identification of concrete, observable behaviours of respectful and disrespectful care. ${ }^{17}$ As such, many participants in this study considered the Footprints 
Project as an intervention promoting respectful care, aligned with the definition that respect is recognition of the unconditional value of patients as persons. ${ }^{18}$

Limitations of this study include a modest number of patient and family interviews. While trainee exposure to Footprints was during short clinical rotations, their reflections resonated with those of permanent clinicians. While potentially serving as a conversation-starter, clinicians cautioned that reading the Footprints tools should not replace spontaneous, authentic dialogue. Clinician impressions about how Footprints has influenced the culture of the unit does not imply causality, nor does vernacular use of the term 'culture' indicate a validated sociologic construct.

Strengths of this study include the mixed-methods design informed by interdisciplinary engagement, and representative views of patients, family members and clinicians. We used a multimodal enabling and reminding approach to enhance and sustain uptake. The Footprints Project also supports individualised care at the end-oflife for dying patients and their families, complementing palliative care interventions in our unit such as the 3 Wishes Project, ${ }^{19}$ aligning with dignity-conserving care ${ }^{20}$ humanising patients whether they survive or succumb.

A recent systematic review ${ }^{21}$ focused on the effect of humanised care of critically ill patients on empathy among healthcare professionals, anxiety among relatives and burnout and compassion fatigue in both groups, Galvin $e t$ al identified 12 studies addressing 4 interventions (liberal visitation, diaries, family participation in basic care and witnessed resuscitation) and 1 mixed intervention. Of 12 studies, 11 were at high risk of bias, 10 measured anxiety among 1055 relatives, 2 measured burnout in 288 ICU professionals and none addressed empathy or compassion fatigue. The effect of humanising interventions on any of these psychological outcomes was not quantifiable, but reviewers identified a trend towards reduced anxiety among families participating in basic patient care, liberal visitation and diary keeping; the effects of liberal visitation on burnout among clinicians was conflicting. This review underscores the potential for this domain of inquiry.

\section{Further research}

Whether the Footprints Project results are generalisable to other wards or jurisdictions merits further evaluation. Exploring the untapped potential of Footprints as a more deliberate bidirectional communication vehicle, or a tool to foster clinician emotional intelligence ${ }^{22}$ would also be worthwhile.

\section{Public and patient involvement}

The motivation for this project was humanising members of the public when they are technologically dependent in the ICU; in this sense, the public motivated the aims of our research. We sought direct input from patients and families about the Footprints Form and Whiteboard through interviews, thereby eliciting advice about their content and format. We solicited their views about whether and how the Footprints Project influenced their experience in the ICU. Their voices motivated us to continue with the Footprints Project. After sharing the preliminary results locally, final study results will be shared with clinicians at local interprofessional rounds and scientific meetings.

\section{CONCLUSIONS}

We explored the uptake, sustainability and influence of Footprints Project from patient, family and clinician perspectives in the ICU. By increasing access to valuable personal information about patients before and beyond their critical illness through personalised whiteboards at the patient's bedside, the Footprints Project facilitates holistic, patient-centred care, informs clinical encounters with patients and families and enhances interprofessional practice.

Acknowledgements The authors would like to thank the patients, families and many clinicians who shared their perspectives through interviews and encouraged to pursue this work. The authors value the initial work by Tammy French, RN, which was a cornerstone of this project. The authors appreciate the support of Drs Anne Boyle and Anne Woods, and the professional transcription assistance of Diana Clancy. The authors would also like to thank Elly Groen, RN for her ongoing volunteer work with the Footprints Project.

Contributors Concept and design: NH, MS, AT, BT, MS, LW, FT, DJC. Acquisition, analysis or interpretation of data: NH, MS, AT, BT, MS, LW, FT, FJC, ED, MS, DJC. Drafting of the manuscript: NH, MS, AT, BT, MS, ED, DJC. Critical revision of the manuscript for important intellectual content: NH, MS, AT, BT, MS, LW, FT, FJC, EHD, MS, DJC. Statistical analysis: AT, BT, MS. Obtained funding: NH, DJC. Administrative, technical or material support: NH, MS, AT, BT, MS, LW, FT, FJC, MS, DJC. Responsibility for the integrity of the data: NH, DJC.

Funding This study was funded by a peer-review grant from the St. Joseph's Hospital Nursing Advisory Council (NH) and the Canadian Institutes for Health Research (DJC). Footprints was supported by a Hamilton Community Grant from the Walmart Foundation, as well as generous donations from families and colleagues in the ICU and broader community through fund-raising efforts led by Dr Michelle Kho, Ms France Clarke and Ms Mary Copland. DJC holds a Canada Research Chair in Critical Care Knowledge Translation from the Canadian Institutes of Health Research.

Competing interests $\mathrm{NH}$ received a grant from the Nursing Advisory Council of St Joseph's Healthcare Canada and a Walmart Community Grant. DJC received a Canada Research Chair from the Canadian Institutes of Health Research which helped to support this work. Otherwise, none of the authors have any competing interests to declare.

Patient consent for publication Not required.

Ethics approval The Hamilton Integrated Research Ethics Board approved this study (Project \#3214).

Provenance and peer review Not commissioned; externally peer reviewed.

Data availability statement Data are available on reasonable request. All data relevant to the study are included in the article or uploaded as supplementary information.

Open access This is an open access article distributed in accordance with the Creative Commons Attribution Non Commercial (CC BY-NC 4.0) license, which permits others to distribute, remix, adapt, build upon this work non-commercially, and license their derivative works on different terms, provided the original work is properly cited, appropriate credit is given, any changes made indicated, and the use is non-commercial. See: http://creativecommons.org/licenses/by-nc/4.0/.

\section{REFERENCES}

1 Koksvik GH. Silent subjects, loud diseases: enactment of personhood in intensive care. Health 2016;20:127-42. 
2 Chochinov HM, McClement S, Hack T, et al. Eliciting personhood within clinical practice: effects on patients, families, and health care providers. J Pain Symptom Manage 2015;49:974-80.

3 Meier DE, Back AL, Morrison RS. The inner life of physicians and care of the seriously ill. JAMA 2001;286:3007-14.

4 Pan JL, Chochinov H, Thompson G, et al. The time questionnaire: a tool for eliciting personhood and enhancing dignity in nursing homes. Geriatr Nurs 2016;37:273-7.

5 Fick DM, DiMeglio B, McDowell JA, et al. Do you know your patient? J Gerontol Nurs 2013;39:2-4.

6 Patak L, Gawlinski A, Fung NI, et al. Communication boards in critical care: patients' views. Appl Nurs Res 2006;19:182-90.

7 Hoad N, French T, Shears M, et al. Personalizing care for critically ill patients: the footprints project. can CRIT care forum Abstract book, 2016: A110.

8 Hoad N, French T, Shears M, et al. Personalizing Care for Critically III Patients: The Footprints Project. In: Canadian critical care forum 2016. Toronto, ON: Can Crit Care Forum Abstract Book, 2016.

9 Hoad N, French T, Shears M, et al. Footprints of Life: Steps in the Development and Implementation of an Interprofessional ICU Initiative to Humanize Health Care. In: Niagara health quality symposium Abstract book, 2016.

$10 \mathrm{Hsieh} \mathrm{H}-\mathrm{F}$, Shannon SE. Three approaches to qualitative content analysis. Qual Health Res 2005;15:1277-88.

11 Rodgers BL, Cowles KV. The qualitative research audit TRAIL: a complex collection of documentation. Res Nurs Health 1993;16:219-26.

12 Sandelowski M. Whatever happened to qualitative description? Res Nurs Health 2000;23:334-40.

13 Abdul-Razzak A, You J, Sherifali D, et al. 'Conditional candour' and 'knowing me': an interpretive description study on patient preferences for physician behaviours during end-of-life communication. BMJ Open 2014;4:e005653.

14 Moniz T, Lingard L, Watling C. Stories doctors tell. JAMA 2017;318:124-5.

15 Gazarian PK, Morrison CRC, Lehmann LS, et al. Patients and care partners' perspectives on dignity and respect during acute care hospitalization. J Patient Saf 2017. doi:10.1097/ PTS.0000000000000353. [Epub ahead of print: 22 Feb 2017].

16 Sokol-Hessner L, Folcarelli PH, Sands KEF. Emotional harm from disrespect: the neglected preventable harm. BMJ Qual Saf 2015;24:550-3.

17 Brown SM, Azoulay E, Benoit D, et al. The practice of respect in the ICU. Am J Respir Crit Care Med 2018;197:1389-95.

18 Beach MC, Duggan PS, Cassel CK, et al. What does 'respect' mean? Exploring the moral obligation of health professionals to respect patients. J Gen Intern Med 2007;22:692-5.

19 Cook D, Swinton M, Toledo F, et al. Personalizing death in the intensive care unit: the 3 wishes project: a mixed-methods study. Ann Intern Med 2015;163:271-9.

20 Chochinov HM. Dignity and the essence of medicine: the A, B, C, and D of dignity conserving care. BMJ 2007;335:184-7.

21 Galvin IM, Leitch J, Gill R, et al. Humanization of critical carepsychological effects on healthcare professionals and relatives: a systematic review. Can J Anesth/J Can Anesth 2018;65:1348-71.

22 Emanuel EJ, Gudbranson E. Does medicine Overemphasize IQ? JAMA 2018;319:651-2.

23 Centofanti JE, Duan EH, Hoad NC, et al. Use of a daily goals checklist for morning ICU rounds: a mixed-methods study. Crit Care Med 2014;42:1797-803. 